\title{
A golden thread? The relationship between supervision, practice and parental engagement in child and family social work.
}

\begin{abstract}
$\underline{\text { Abstract }}$
Within the social work profession, supervision is highly valued. Yet it is not clear how supervision supports good practice or how supervision makes a difference for children and families. In this study, using paired observations of group supervision and family meetings alongside interviews with parents, we explored the link between supervision, practice and engagement. Considering each data set separately, we found a range of skill levels within the supervision discussions and in the meetings with families. Parents reported generally high levels of satisfaction with the service and in relation to their individual worker. But more importantly, we found a 'golden thread' between certain elements of supervision, more skilful practice and improved parental engagement. We discuss these key elements in detail and consider what these findings tell us about good supervision and what difference it can make for families and children.
\end{abstract}

\section{$\underline{\text { Introduction }}$}

Every child and family social worker is expected to receive regular supervision (Local Government Association, 2014) despite the paucity of empirical evidence that it helps improve practice or outcomes for children and families (Carpenter, Webb and Bostock, 2013). There is some data, mainly from the US, to suggest that 'good supervision' improves worker satisfaction and retention (Ellet, 2008; Mor Barak et al., 2009). No doubt these are useful outcomes. Yet they are not the stated aims of UK social work supervision. Instead, supervision is intended to "ensure quality of service for people who use [them]" (British Association of Social Workers, 2011, p.7) and to "generate better outcomes for children and families" (Department for Education, 2015, p.6). Despite a growing interest in the field, a recent international Delphi study concluded that the focus of supervision research needs to change from self-report to empirical observation and analysis (Beddoe et al., 2016). This refocused effort should, in our view, ask not 'how does supervision make a difference for workers?' but 'how does supervision make a difference for children and families?'. To aid these efforts, the study presented in this paper reports a direct association between what happens in supervision and parental engagement and goal-agreement within the context of child protection services in England. 


\section{Background}

In 1991, Harkness and Hensley reported the findings from an experimental study of supervision in the field of adult mental health. They organised for the provision of supervision to four social workers over a 16-week period and measured three dimensions of client satisfaction. 161 clients took part and answered questions about their mental health (using the Generalized Contentment Scale; Hudson, 1982) and their satisfaction with the service (using Client Satisfaction Scales; Poertner, 1986). In the first 8-weeks of the study, the workers were provided with two hours of supervision per week with a 'mixed-focus'. In the second 8-weeks of the study, the supervision was provided with a 'client-focus'. Mixedfocus supervision included "administration, training and clinical consultation" (Harkness and Hensley, 1991, p.507). Client-focused supervision considered instead the "client's conceptualizations of the presenting problem, helping and outcomes", with the aim of helping workers to "evaluate their practice in light of [these] conceptualizations, predictions and outcomes" (ibid, p.507). To illustrate, Harkness and Hensley provide examples of the kinds of questions discussed within client-focused supervision- "What does the client want help with? How will you and the client know you are helping? How does the client describe a successful outcome? What are you doing to help the client? How will that work? Does the client say that will help?" (ibid, p.507). Following the change from mixed-focus to clientfocused supervision, Harkness and Hensley found a 10 per cent improvement in client satisfaction with goal attainment, a 20 per cent improvement in satisfaction with worker helpfulness and a 30 per cent improvement in satisfaction with the partnership between client and practitioner (ibid, p.510). Although these are moderate effect sizes (Cohen, 1977), given the simplicity of the intervention, they are nevertheless very significant. To our knowledge, and despite the promising findings, the study has never been repeated and certainly not in the context of child protection social work.

In 2017, Bostock et al. published an evaluation of a Department for Education-funded programme to 'scale and deepen' the use of the 'Reclaiming Model of Social Work' in five "very different local authorities" (Bostock et al., 2017, p.8). As part of the evaluation, regular observations were made of social workers in direct practice with families, usually during home visits (ibid, p.79). These were "recorded and coded for key social work skills using a... framework with established reliability (Whittaker et al., 2016, p.18)". Twenty-two of the workers observed during home visits were also observed during group supervision discussions. These supervision sessions were coded independently from the practice observations using a "systemic observation framework" (ibid, p.6). (Further details about these frameworks and the coding process can be found in the report; Bostock et al., 2017, 
p.80-81). Based on this framework, each supervision session was rated as 'not systemic' ( $\mathrm{n}=$ 4, 18 per cent), as showing the 'green shoots' of systemic practice ( $\mathrm{n}=9,41$ per cent) or as 'fully systemic' ( $\mathrm{n}=9,41$ per cent; $\mathrm{p}$. 46). The study found a "strong relationship between the quality of systemic case discussion and the quality of practice $(r=0.456, p=0.04)$." (ibid, p.46). The average practice score associated with non-systemic group supervision was 2.35 . The average practice score associated with 'green shoots' or 'fully systemic' group supervision was 3.43. While these effect sizes are moderate, this ground-breaking study was the first to report a positive relationship between 'good supervision' and improved practice within the specific context of child and family social work in England.

In this paper, we investigate the same relationship between group supervision case discussions and practice skill, albeit applying a different analytical framework for supervision. That we arrive at similar findings adds weight to the conclusions drawn by Bostock et al. (2017). In addition, we investigate the association between what happens in group supervision and how parents experience and evaluate the service they receive. Thus, we draw a 'golden thread' between supervision, practice and (a form of) outcomes.

\section{$\underline{\text { Research design }}$}

Background

The current study took place in early 2017 in a south east local authority. Following a series of 'inadequate' Ofsted judgements, the children's services department has been significantly reconfigured. Previously, practitioners and managers operated in 'traditional' teams, with around six social workers individually responsible for a case load and supervised by a team manager. Now, social workers have been reorganised into small units (or hubs), alongside family therapists or other clinicians, business support officers and child and family practitioners (Goodman and Trowler, 2011). These units between them share elements of case responsibility and seek to work more collectively with families. One key component of the unit model is a regular group supervision meeting, in which families and case work are discussed communally. At the outset of our study, 12 hubs had been set up and all staff had attended at least a two-day introductory training course on systemic social work practice. The authority, wanting to know more about how this new approach was working, asked the Tilda Goldberg Centre for Social Work and Social Care (TGC) to undertake a small exploratory study.

Data collection took place over a 4-month period. During this time, each social worker taking part was asked to select one family for the research. If the family consented, they were included in the sample. If the family did not consent, they were not included and the practitioner was asked to identify another family (Figure 1). 
The primary aim of the project was to explore how the new hub model was working. Our three research questions were:

- What happens in group supervision case discussions?

- How does group supervision relate to what happens in family visits?

- How does group supervision relate to families' experience of the service?

To address these questions, we used a mixed-methods design combining observations and audio-recordings of practice and supervision and interviews with social workers and family members. The main purpose of using a mixed-methods design was to avoid the limitations of self-report methods for evaluation. Typically, when researching social work supervision, supervisors and practitioners are asked about their experiences of supervision. While valuable, such approaches cannot tell us about the relationship between different approaches to supervision, practice skill and outcomes for families (Whittaker et al., 2016, p.49).

\section{Participants}

Twenty-one families participated in observations of family visits. Of these, nineteen gave consent for their family visit to be audio-recorded as well as observed. Two families agreed to being observed but not audio-recorded. Nineteen family interviews were also completed - fourteen with mothers, three with mothers and fathers, and two with young people. In addition, thirty-three professionals took part in twenty-two observed group supervision discussions. This included one senior manager, three Consultant Social Workers, two senior social workers, 8 social workers, 2 student social workers, 7 child and family workers, two clinicians and three administrators. In addition, twenty-two case questionnaires were completed by social workers about each family (Table 1).

\section{Sampling}

Sampling took place in two ways. First, information about the project was circulated to all members of staff and all twelve hubs were asked if they wanted to take part. Six hubs volunteered and three of these were selected to participate by the Head of Operations based 
on longevity. (The more established hubs were thought more likely to have embedded systemic ways of working than the newer hubs.) Two of these hubs worked with children subject to child protection plans and the third was an 'early help' hub.

Second, each hub was asked to identify up to eight families for the research. Hubs were asked to consider criteria such as the length of time since referral, reasons for involvement and the age of the child/ren, to obtain a relatively mixed sample.

\section{Data collection}

For each family, the intention was to collect four types of data using three different methods (observations, questionnaires and interviews). First, a group supervision case discussion about the family was observed and audio-recorded by a researcher. Second, the lead worker for the family was asked to complete a case questionnaire, providing background information such as length of time since referral, reasons for involvement and the severity and nature of perceived risk or need. Third, the worker's subsequent visit to the family was observed and audio-recorded by a researcher. Finally, one or more family members were interviewed about their experiences of the service, their relationship with the worker in the family visit and their understanding about the goals for the work.

\section{Analysis}

Audio recordings of supervision and family visits were analysed by a team of researchers using two bespoke coding frameworks. These analyses were conducted independently by researchers not otherwise involved with the project. The coding team were 'blind' to other information about the family, apart from what they heard on the recording. Recordings of supervision and family visits were analysed independently (not by the same researcher).

\section{Coding framework for group supervision discussions}

The supervision coding framework supervision was developed by researchers at TGC in consultation with practitioners and managers from a central London local authority (Wilkins et al., forthcoming). The framework includes five dimensions - analysis and critical thinking; clarity about risk or need; collaboration; focus on the child and family and support for practice. Each dimension is coded on a three-point scale (1, 3 or 5). ' 1 ' indicates the dimension is 'not present' in the discussion, ' 3 ' indicates the dimension is 'somewhat 
present' and ' 5 ' indicates the dimension is 'significantly present'. The framework is currently unpublished but an overview is provided in Table 2 .

\section{Coding framework for family visits}

Family visits were analysed using a more established coding framework for social work practice (Whittaker et al., 2016). This framework was initially developed based on the Motivational Interviewing Treatment Integrity (MITI) manual (Moyers et al., 2010), adapted for use in an English statutory child and family social work context. Studies across different local authorities found that although the MITI captured some key elements of good practice (e.g. empathy and collaboration), it needed to be extended in order to capture and reflect the specific context of child and family social work. Further dimensions were then developed and added to the MITI. These dimensions emerged from a consideration of the relevant literature and from a series of seminars with leading academics, practitioners and senior managers from the sector (Whittaker et al., p.50-54). This led to the current version of the framework containing seven practice skills - autonomy, collaboration, empathy, purposefulness, clarity about risk, child focus and evocation. Each skill is coded on a five-point scale (1, 2, 3, 4 or 5 ), where ' 1 ' indicates a low level of skill and ' 5 ' a high level of skill. Six of the skills are aggregated into two categories (Forrester and Killian, forthcoming) - 'care and engagement', a combination of autonomy, collaboration and empathy, and 'good authority' (Ferguson, 2011), a combination of purposefulness, clarity about risk and child focus. Evocation is only coded for when there is a clear discussion about behaviour change issue (Bundy, 2004). This results in each audio recording being assigned two category ratings - for care and engagement and good authority - and, if applicable, a rating for evocation. Previous studies have found a significant but moderate association between higher practice skills (measured using this framework) and parental engagement (Forrester et al., forthcoming).

\section{The relationship between the different methods}

Observations of supervision and practice were compared using the two coding frameworks outlined above. The application of these frameworks allowed us to explore the relationship between different approaches to supervision and practice. Interviews with family members provided data for the third link in this chain of supervision to practice to parental engagement. Interviews with social workers were not used to inform our exploration of this three-link chain but to inform our analysis of the supervision and practice sessions by providing background and contextual information. 


\section{Ethics}

The study received approval from the Faculty of Health and Social Sciences' ethics committee of the authors' university. Verbal consent was obtained from each parent prior to the observations of group supervision. Written consent was obtained prior to the family visit observation. Families were informed of their right to withdraw at any point up to the end of data collection and to have all materials collected up to that point deleted. In agreement with the authority, any serious concerns of malpractice were to be reported to the Chief Executive Officer of the organisation and, if necessary, to the Health and Care Professions Council. This did not occur.

\section{Strengths and limitations}

Our study has two key strengths and two key limitations. First, the study is based on actual observations of supervision, rather than self-report measures. Second, data from different methods were analysed independently, making our conclusions more reliable.

However, our sample size is small and based entirely within one local authority. This may limit the applicability of our findings to other areas. Furthermore, the sampling of both professionals and families was selective and those who took part may not represent the broader population. We do not know, for example, how many families were approached by social workers and declined to take part. Finally, we used a developing measure for assessing the quality of supervision and although the results presented here may suggest it has a degree of validity, it has yet to be properly tested and examined.

\section{Findings}

\section{Description of supervision and family visit observations}

Twenty-two group supervision discussions were observed. Attendance ranged from five to fourteen people. Case discussions ranged from 11 to 59 minutes, with a mean of 33 minutes. The session structure was reasonably consistent across the three hubs and from one case discussion to the next. Typically, the allocated worker provided background information about the family and an update on recent activity. Other attendees would then ask questions, make comments and suggest ideas. Many of the discussions included a review of previous actions and agreement of future actions.

We also observed twenty-one family visits. Nineteen took place in the family home, one in the office and one in a local Children's Centre. There were no other professionals 
involved apart from the allocated worker, all of whom were female. The majority involved just one parent. In four of the meetings, the mother and father were present but no fathers were observed alone. In two of the meetings, a child was present and another two involved a young person alone. None of the meetings used an interpreter.

\section{Group supervision discussions - coding analysis}

Using the supervision framework outlined above, we rated the quality of each case discussion (Table 3). The size of the sample is too small to explore whether there were any meaningful differences between different hubs or different types of case (e.g. child protection or child in need).

\section{Family visits - coding analysis}

Using the coding framework developed by Whittaker et al. (2016), we rated the skills demonstrated by workers in family visits (Table 3). The two recordings involving children seen alone were not coded for child focus. The overall score is an average of the six dimension scores (or seven if evocation is included).

To place these results in context, the same framework has been used in several other studies and workers typically score between two and two and a half overall, with moderately higher scores for 'good authority' than for 'care and engagement' (Bostock et al., 2017; Forrester et al., 2017).

\section{Parent interviews}

Based on the family interviews, twelve out of 17 parents $(71 \%)$ said they were pleased with the service overall. Parents generally reported positive experiences of the social worker's involvement and the quality of help provided (Tables 5 and 6). Of the twelve parents with previous experience of social services, eleven (92\%) said their current experience was better.

\section{Shared goals}

Most parents said they had a good understanding about the goals of the work (Table 7). In eight of the 16 cases (50\%), the goals of the worker and parent were closely matched (in one of the seventeen completed interviews, the parent did not answer this question for reasons unknown). In the other eight cases (50\%), the goals were not closely matched, 
although in six of these cases, the parent believed they had the same goal as the worker. In the other two cases, the parent knew they did not share the worker's goal.

\section{The relationship between supervision and practice skills}

We compared the quality of supervision discussions and the quality of social work practice in family visits. We found significant associations between one dimension of supervision ('support for practice') and two dimensions of practice: 'good authority' and overall practice skills (Table 8).

To explore this association further, we placed each supervision discussion into one of two categories - 'practice-focused' or 'other-focused'. Supervision discussions that scored ' 3 ' or ' 5 ' on the 'support for practice' dimension were included in the former $(n=9)$. Those that scored ' 1 ' were included in the latter $(n=13)$. Practice scores associated with the 'practice-focused' category were consistently higher than the "other-focused" category (Table 9). These differences were significant for the practice skill category of 'good authority' $(\mathrm{t}(15)=.-3.14, \mathrm{p}=.007)$ and for overall skill $(\mathrm{t}(15)=-3.09, \mathrm{p}=.008)$ but not for 'care and engagement'.

The following four extracts from selected supervision recordings demonstrate some of the differences between practice- and other- focused supervision. By providing these extracts, we hope to show with some degree of specificity what these differences 'look like' in practice.

In the first example, explicit links were made between perceived risks to the child, the work that had already been done and the work that still needed to be done. Although the session began with a summary of activity, talk quickly turned to an evaluation of what this activity had achieved in relation to the risks. The social worker identified a need for "some parenting work with Mum" because this is what "[the mother] has requested". The group then discussed what elements of parenting the worker might want to focus on and by the end, the worker had a clear plan for her next home visit. The discussion included an agreement about what the worker was going to do ('some parenting work with mum'), why she was going to do it ('[the mother] has requested [it]') and how the worker could start this work in the next home visit.

In the second example, the worker was interested in exploring the father's own experiences of being cared for as a child. The supervisor helped the worker think about the kinds of questions she might ask, linking this to previous direct work completed with the child - "he may want to have more physical affection, he maybe doesn't know it or can't say 
it yet? So, questions like 'how did your dad show affection' or 'how did your parents show affection [might help]'? The social worker responded by saying, "Yeah, I hadn't really thought about specific questions but yeah, what kinds of things did he do with his dad, trying to get to the affection side of things, that's a good question to ask".

In the third example, the supervisor suggests that she and the worker think about her next conversation with the mother.

Sup: So, we can have a think about what you might do next?

SW: Absolutely. I need to follow up, I might put in a quick visit later... and sit down with [mother].

Sup: If she has time for a chat today, maybe 5 minutes, [you could say] that's great that you went [to the alcohol service], how are you feeling about going tomorrow? SW: Yep, if I don't visit today, I'll call her.

Sup: That's great. And reinforce about her going tomorrow.

SW: Whether I visit today or not, I'll certainly sit down with her and explore a bit more about how it goes tomorrow, it'll be new and her initial feelings about that. Sup: The other thing we talked about was a session with her, looking at things she's achieved and then a sheet with things she's still working on...helping her see you've come this far but let's try and work on these things because you don't want to go backwards.

As in these examples, practice-focused supervision does not necessarily entail a very long discussion. It can be as simple as deciding on some questions for the social worker to ask in the next visit and being clear about why. 'Other-focused' supervision often did not include a clear agreement about future actions or the rationale for them. Instead, they tended to be characterized by: a lack of structure, a focus on the past and a superficial discussion of problems and issues. There was often no sense that the social worker, or other members of the group, understood the family or had a clear idea about where the case was headed. Members of the group might ask lots of questions about a whole range of issues, but with many of them going unexplored and unanswered. In many examples, no single issue was discussed in-depth and there was no attempt to prioritise what might be the most important issues. These factors seemed to operate as a barrier to more 'practice-focused' discussions. The following extract demonstrates the flavor, if not the extent, of these sessions: 
Sup: How old is he? 2?

SW: Two.

Sup: And we've been involved since?

SW: We got the referral when he was born, mind you, dad's had two children

removed from his care previously.

Sup: What for?

SW: Neglect. For adoption.

Sup: The prognosis is?

SW: Not very good

Sup: No.

Sup: When are the family moving?

SW: They got the keys last Friday I'm told so over the weekend they were meant to be moving stuff.

Sup: Because I would kind of watch that initially.

The relationship between supervision, parental experiences, goal-agreement and life rating

We then compared the quality of supervision, parental engagement, goal-agreement and life-rating measures, using the same 'practice-focused' or 'other-focused' categories. For all these areas, scores were higher in the 'practice-focused' category than the 'other-focused' category (Table 10). These differences were significant for goal agreement $(\mathrm{t}(14)=-2.675$, $\mathrm{p}=.018$ ) but not for the other variables.

Summary of findings

We now return to our three research questions and summarise the key findings from the study (Figure 2):

- What happens in group supervision case discussions?

- Group supervision discussions scored relatively highly for 'family and child focus' and 'clarity about risk' and relatively poorly for 'collaboration' and 'support for practice'.

- How does group supervision relate to what happens in family visits? 
○ Where supervision was 'practice-focused', there was a positive association with more skillful social work practice, particularly the use of 'good authority' (purposefulness, clarity about risk and child focus).

- How does families' experience of the service relate to what happens in group supervision?

○ 'Practice-focused' supervision discussions were also associated with higher levels of parental engagement and goal-agreement (Figure 2).

\section{$\underline{\text { Discussion }}$}

Understanding how good supervision supports good practice and helps improve parental engagement and goal-agreement is a complicated task. The number of variables that would have to 'line up' to support such a relationship is high (Fleming and Steen, 2004). And yet the belief that good supervision supports good practice and leads to better outcomes (including better engagement) for service users is widespread (Kettle, 2015). In this paper, we have described a golden-thread between supervision (of a particular type), improved practice skills (measured in a certain way) and better parental engagement and goalagreement (within a specific context). The starting point of this golden thread is 'practicefocused' supervision - but what does this mean? Broadly, practice-focused supervision seeks to answer three key questions:

1. What is the social worker going to do next?

2. Why is the social worker going to do those things?

3. How is the social worker going to do these things?

Sessions that score highly are characterized by a sustained curiosity about practice and a sense that the responsibility for achieving good outcomes is shared between supervisor and supervisee. Supervisors and supervisees will discuss clearly why they are going to do these things rather than those things and will consider how best to share this rationale with the family. The discussion will also include an exploration of how to complete these tasks. For example, if the agreed action is for the worker to talk to a father about how his mental health difficulties are impacting his parenting, the supervisor will spend time helping the worker think how best to have this conversation. Would it be better to talk about it in the office or at home? Would the father feel more comfortable if his partner were present or not? How can we explain to the father why we think this matters? What kinds of questions might 
lead to openness and self-reflection? What kinds of questions might lead to resistance and defensiveness? How might the worker respond if the father becomes anxious or angry? And how would we know if the conversation was helpful or not and for whom? When deciding whether the session is practice-focused or not, researchers are encouraged to consider the following three questions:

1. Do you know what the social worker is going to do in the next home visit or the next few home visits with the family?

2. Do you understand why the social worker is going to do these things and how?

3. Has this discussion helped the social worker think more carefully about what they are going to do, how and why?

On the other hand, 'other-focused' supervision sessions tend to be characterized by a lack of curiosity and a sense that the quality of the social worker's practice is his or her responsibility alone. There may be no discussion about what the social worker is going to do or these discussions will relate to procedure and process (e.g. completing an assessment, referring to other services, completing a visit on time) rather than practice. There will be no discussion - or only a very limited discussion - about why these actions are important or how they might be completed in the family's best interests. For example, the supervisor might advise the social worker to talk to the mother about her partner's suspected drug misuse but offer no guidance about how nor make explicit why this particular action (as opposed to all the other potential and equally-as-reasonable actions one could take) and why now.

\section{Implications for practice: Creating the conditions for practice-focused supervision}

Achieving more 'practice-focused' supervision is not as simple as asking in case discussions more 'what', 'why' and 'how' questions. For a start, within the context of a mistrustful supervisory relationship, where the focus may be on accountability and management oversight, a question such as "why are you thinking of doing that?" is likely to provoke a defensive response rather than a reflective one. Being able to think and talk openly with a supervisor about how and why you practice requires a degree of mutual trust and respect. But assuming such a relationship does exist, there seem to be (at least) three necessary conditions for more practice-focused supervision. Many of the best 'practicefocused' sessions in this study were characterized by a respectful curiosity about families. Even in situations of high risk, social workers and their supervisors had a genuine desire to 
understand. For example, we observed one session in which the risk of physical harm from domestic abuse was very high. Part of the discussion involved thinking about why the mother might 'want' to remain in a violent relationship or what barriers might be preventing her from leaving. It was easy to imagine how the same kind of questions ('why would she want to stay? What are we missing about the relationship that makes it hard for us to understand?') might be posed very differently and more punitively without a foundation of respect and genuine curiosity ('why on earth would anyone stay in that situation? What kind of person would make such a horrible decision?').

From this foundation, we identified two other conditions that helped inform more practice-focused discussions - 'child and family focus' and 'clarity about risk or need' (Figure 3). The first involves a consideration of what life is like for different family members and in particular the child/ren. The second involves an explicit discussion about risk (or need) including - what harm have the children experienced? What harm might they experience in future? How likely is this harm to occur? What do other people, including the child and the family, think about these risks? And is the level of risk increasing, decreasing or staying the same? Clarity about these two things ('child and family focus' and 'clarity about risk or need') often helped inform the three 'support for practice' questions - what are we going to do? Why? And how?

\section{Conclusion}

In this paper, we have described a 'golden thread' between supervision, practice, parental engagement and goal-agreement. By focusing on how supervision helps families, rather than social workers, we hope to contribute to the developing debate about the effectiveness of supervision in the context of child and family social work in England. For several reasons, we have deliberately avoided a discussion of particular models of supervision or the provision of a list of questions to ask in order to achieve more practicefocused discussions. First, because there are already many excellent supervision models available and our aim at this stage is not to develop another one. Second, because providing practice-focused supervision probably depends more on attitudes and values than it does on what might otherwise become a tick-box list of questions to get through. And third, because although our findings may be promising, they are best considered as a series of case studies rather than a robust evaluation. As ever, more research is needed - in this case, the implementation on a wider scale, in more than one local authority, of an existing model of practice-focused supervision to which fidelity can be reliably measured (perhaps by using the 
framework we are developing and have trialed in this study), followed by an experimental evaluation of whether and how it works - or not - in widespread practice. And fourth, because the provision of good supervision is not merely the responsibility of supervisors and supervisees. Where managers are finding it hard to provide more helpful, practice-focused supervision, we do need to ask whether they have the right skills to perform the job effectively but we also need to question what support they have been given, whether they have had proper training, whether they get proper support from their own managers and whether they have adequate time and space to think about the complexity of the task they have been given.

Nevertheless, as the basis for a thoughtful consideration of what good supervision 'looks like' in the context of child and family social work, we hope this paper has provided a useful starting point (or way marker) for considering how supervision can support improved practice skills but more importantly help increase parental engagement and goal-agreement as part of the journey towards improved outcomes for families and children.

\section{$\underline{\text { References }}$}

1. Beddoe, L., Karvinen-Niinikoski, S., Ruch, G. and Ming-sum, Tsui. (2016). Towards an International Consensus on a Research Agenda for Social Work Supervision: Report on the First Survey of a Delphi Study. British Journal of Social Work, 6(1), pp. 1568 1586.

2. Bostock, L., Forrester, D., Patrizo, L., Godfrey, T., Zonouzi, M. (2017). Scaling and deepening the Reclaiming Social Work Model. Available from: http://cdn.basw.co.uk/upload/basw_92552-3.pdf [Accessed 4 October 2017].

3. British Association of Social Workers (2011). UK Supervision Policy. Available from: http://cdn.basw.co.uk/upload/basw_73346-6.pdf [Accessed 4 October 2017].

4. Bundy, C. (2004) Changing behaviour: using motivational interviewing techniques. Journal of the Royal Society of Medicine, 97(44), pp. 43 - 47.

5. Carpenter J., Webb C.M, Bostock L. (2013). The surprisingly weak evidence base for supervision: Findings from a systematic review of research in child welfare practice (2000-2012). Children and Youth Services Review, 35, pp. 1843-1853.

6. Cohen, J. (1977) Statistical power analysis for the behavioral sciences (revised edition). New York. Academic Press. 
7. Department for Education (2015). Knowledge and skills statements for practice leaders and practice supervisors. Available from: http://cdn.basw.co.uk/upload/basw_10501110.pdf [Accessed 4 October 2017].

8. Ellett, A. (2008). Intentions to remain in child welfare: the role of human caring, selfefficacy beliefs, and professional organizational culture. Children and Youth Services Review, 31(1), pp. 78-88.

9. Ferguson, H. (2011). Child Protection Practice. London. Palgrave.

10. Fleming I and Steen L (2004) Introduction in I Fleming and L Steen (eds) Supervision and clinical psychology: theory, practice and perspectives, 2nd edn, London: Routledge

11. Forrester, D., Lynch, A., Bostock, L., Newlands, F., Preston, B. and Cary, A. (2017) Family Safeguarding Hertfordshire. Available from: http://cdn.basw.co.uk/upload/basw_75050-4.pdf [Accessed 4 October 2017].

12. Forrester, D., Westlake, D., Whittaker, C., Thomas, R., Waits, C., Antonopoulou, V., Killian, M. and Hutchison, D. (forthcoming) What works in engaging parents in child protection work? A study of practice skills, engagement and outcomes for 131 families, British Journal of Social Work.

13. Goodman, S. and Trowler, I. (2011) Social work reclaimed. London. Jessica Kingsley Publishers.

14. Harkness, D. and Hensley, H. (1991). Changing the focus of social work supervision: effects on client satisfaction and generalised contentment, Social Work, 36(6), pp.506512.

15. Hudson, W. (1982). The clinical measurement package. Homewood, Illinois. Dorsey Press.

16. Kettle, M. (2015) Achieving effective supervision. Available at: https://www.iriss.org.uk/resources/insights/achieving-effective-supervision [Accessed 8th October 2017].

17. Local Government Association (2014). The Standards for employers of Social Workers in England. Available from https://www.local.gov.uk/sites/default/files/documents/download-what-you-should-2f9.pdf [Accessed 4 October 2017].

18. Mor Barak, M., Travis, D., Pyun, H. and Xie, B. (2009). The impact of supervision on worker outcomes: A meta-analysis. Social Service Review, 83(1), pp. 3 - 32.

19. Moyers, T.B., Martin, T., Manuel, J.K., Hendrickson, S.M., \& Miller, W. R. (2005). 
Assessing competence in the use of motivational interviewing. Journal of Substance Abuse Treatment, 28(1), pp. 19-26.

20. Poertner, J. (1986). The use of client-feedback to improve practice: Defining the supervisor's role. The Clinical Supervisor, 4(4), pp. 57 - 67.

21. Whittaker, C., Forrester, D., Killian, M., and Jones, R. (2017). Can we reliably measure social work communication skills? Development of a scale to measure child and family social work direct practice. International Journal of Child \& Family Welfare, 17(1/2), pp. $47-63$.

22. Wilkins, D., Stabler, L., McDonald, J., Westlake, D., Carro, H., Newlands, F., Khan, M. and Lynch, A. (forthcoming) Assessing the quality of supervision case discussions in child and family social work: the development of a coding framework. 